\title{
Adenosquamous Carcinoma Affecting the Maxilla: A Case Report and Review
}

\section{Marcos Martins Curi ${ }^{1}$, Marcelo Ferraz de Oliveira ${ }^{2}$, Anthony Froy Benites Condezo ${ }^{3 *}$, Heliton Gustavo Lima ${ }^{4}$, Andréia Aparecida da Silva ${ }^{3}$, Carlos César DeAntoni ${ }^{3}$, Camila Lopes Cardoso ${ }^{3}$}

\author{
${ }^{1}$ Department of Oral and Maxillofacial Surgery, Hospital Santa Catarina, São Paulo, Brazil \\ ${ }^{2}$ Department of Implantology, P-I Branemark Institute, São Paulo, Brazil \\ ${ }^{3}$ Department of Oral Surgery, Universidade do Sagrado Coração, São Paulo, Brazil \\ ${ }^{4}$ Department on Oral Pathology, University of São Paulo, São Paulo, Brazil \\ Email: *Anthonybenitea@gmail.com
}

How to cite this paper: Curi, M.M., de Oliveira, M.F., Condezo, A.F.B., Lima, H.G., da Silva, A.A., DeAntoni, C.C. and Cardoso, C.L. (2017) Adenosquamous Carcinoma Affecting the Maxilla: A Case Report and Review. Journal of Cancer Therapy, 8, 286-295.

https://doi.org/10.4236/jct.2017.83024

Received: February 21, 2017

Accepted: March 28, 2017

Published: March 31, 2017

Copyright $\odot 2017$ by authors and Scientific Research Publishing Inc. This work is licensed under the Creative Commons Attribution International License (CC BY 4.0).

http://creativecommons.org/licenses/by/4.0/

\begin{abstract}
Adenosquamous carcinoma of the head and neck (ASC) is a rare and aggressive variant of squamous cell carcinoma, a locally aggressive malignancy characterized by the presence of two distinct components: a squamous cell carcinoma and an adenocarcinoma. The purpose of this study was to report an additional rare case of adenosquamous carcinoma affecting the maxilla, with clinical microscopic features and a complex mid-facial rehabilitation.
\end{abstract}

\section{Keywords}

Squamous Cell Carcinoma, Adenosquamous Carcinoma, Implant Supported Prosthesis, Maxillofacial Rehabilitation

\section{Introduction}

Adenosquamous carcinoma (ASC), first described in 1968 [1], is an unusual and highly malignant neoplasm, which is characterized microscopically by the simultaneous presence of distinct areas of adenocarcinoma and squamous cell carcinoma (SCC) [1] [2]. There are controversies about the exact histogenesis of ASC. One hypothesis is that neoplasm arises from carcinoma in situ of minor salivary glands and ductal epithelial tissues. However, recently, authors [3] have strongly suggested that oral ASC is derived only from the squamous superficial epithelium, without the participation of minor salivary glands [3] [4]. The most common clinical feature is a painful mucosal ulceration [1] [2] [3] [4] [5]. Cigarette smoking and alcohol consumption, have been implicated as etiologic agents. There is a male predilection, with a tendency to develop between the sixth and 
seventh decades of life [2]. ASC has an aggressive behavior associated with a poor prognosis. The spread to cervical lymph nodes is common and there are frequent reports on loco-regional and distant recurrences after treatment [1]-[8]. Current treatment options include surgery and radiation therapy with or without chemotherapy. A review of the English-language literature, conducted from 1968 to 2016, using the MEDLINE database showed only 24 well-documented cases of the ASC affecting the mid-face site (Table 1) [1]-[16]. Therefore, the present article describes an ASC affecting the maxilla with clinical and microscopic features and a complex mid-facial rehabilitation.

Table 1. Cases of adenosquamous carcinoma in the midface.

\begin{tabular}{|c|c|c|c|c|c|c|c|c|}
\hline $\begin{array}{l}\text { Case } \\
\mathrm{n}^{\circ}\end{array}$ & Authors & Year & Age & Sex & Location & Treatment & Recurrence & $\begin{array}{l}\text { Follow-up } \\
\text { (months) }\end{array}$ \\
\hline 1 & $\begin{array}{c}\text { Gerughty } \\
\text { et al. [1] }\end{array}$ & 1968 & 76 & $\mathrm{~F}$ & Nose & $S+R$ & Yes & AWD (24) \\
\hline 2 & & & 58 & $\mathrm{M}$ & Nose & $S+R$ & Yes & AWD (36) \\
\hline 3 & Sanner [2] & 1979 & 60 & $\mathrm{M}$ & Maxillary Sinus & S & - & - \\
\hline 4 & $\begin{array}{l}\text { Minic and } \\
\text { Stajcic [3] }\end{array}$ & 1994 & 72 & $\mathrm{~F}$ & Inferior Turbinate & S & No & AWOD (18) \\
\hline 5 & Napier et al. [4] & 1995 & 61 & $\mathrm{~F}$ & Maxillary Alveolus & $S+R$ & Yes & DOD (26) \\
\hline 6 & Som et al. [5] & 1997 & 62 & $\mathrm{~F}$ & Facial Bones, Skull Base and Calvaria & IB & - & - \\
\hline 7 & Alos et al. [6] & 2004 & 71 & $\mathrm{M}$ & Nasal Cavity & S & Yes & DOD (24) \\
\hline 8 & & & 61 & $\mathrm{M}$ & Nasal Cavity & S & Yes & DOD (30) \\
\hline 9 & $\begin{array}{c}\text { Shinhar and } \\
\text { Heckathorn [7] }\end{array}$ & 2008 & 54 & $\mathrm{~F}$ & Nasal Cavity & $S+R$ & No & AWOD (6) \\
\hline 10 & Suzuki et al. [8] & 2009 & 77 & $\mathrm{M}$ & Maxillary Sinus & $S+C+R+S-1$ & Yes & DOD (34) \\
\hline 11 & Masand et al. [9] & 2011 & 82 & $\mathrm{M}$ & Paranasal Sinus & - & Yes & DOD (2) \\
\hline 12 & & & 52 & $\mathrm{M}$ & Nose/Hard Palate/Maxilla & S & Yes & DOD (4.5) \\
\hline 13 & & & 62 & $\mathrm{M}$ & Nasal Cavity & S & No & AWOD (26) \\
\hline 14 & $\begin{array}{l}\text { Kumar and } \\
\text { Issing [10] }\end{array}$ & 2011 & 66 & $\mathrm{~F}$ & Paranasal Sinus & IB & - & - \\
\hline 15 & $\begin{array}{l}\text { Schick } \\
\text { et al. }[11]\end{array}$ & 2013 & 60 & - & Maxillary Sinus & $S+R$ & Yes & DOD (39) \\
\hline 16 & & & 57 & - & Maxillary Sinus & $S+R$ & Yes & AWOD (52) \\
\hline 17 & & & 54 & - & Nasopharynx & $\mathrm{R}$ & Yes & DOD (39) \\
\hline 18 & $\begin{array}{c}\text { Bishop } \\
\text { et al. [12] }\end{array}$ & 2013 & - & - & Sinonasal Tract & - & - & - \\
\hline 19 & & & - & - & Sinonasal Tract & - & - & - \\
\hline 20 & & & - & - & Sinonasal Tract & - & - & - \\
\hline 21 & & & - & - & Sinonasal Tract & - & - & - \\
\hline 22 & & & - & - & Sinonasal Tract & - & - & - \\
\hline 23 & & & - & - & Sinonasal Tract & - & - & - \\
\hline 24 & $\begin{array}{c}\text { Thanakappan } \\
\text { et al. }[17]\end{array}$ & 2015 & 55 & $\mathrm{M}$ & Maxilla & - & - & - \\
\hline
\end{tabular}

-Information not provided; M, Male; F, Female; S, Surgery; R, Radiotherapy; C, Chemotherapy; S-1, A novel oral fluoropyrimidine anticancer agent; IB, Incisional Biopsy; DOD, Dead of disease; AWOD, Alive without disease; AWD, Alive with disease. 


\section{Case Report}

A 47-year-old Caucasian woman was referred to our Institution complaining of pain in the left maxilla associated with nasal bleeding for the last 6 months. There was nothing relevant in her past medical history and she seemed healthy. Intraoral examination revealed asymptomatic nodular lesion in the left hard palate, covered by mucosa with normal color and resilient palpation. The imaging findings revealed a multicystic radiolucent lesion extending from the right upper lateral incisor to the second upper left premolar with poorly defined margins and causing root resorption of the involved teeth. CT scan showed the lesion in the anterior region of both maxillas, which extended mainly to the left maxillary sinus and nasal cavity (Figure 1).

An incisional biopsy was performed and microscopic examination of the hematoxylin and eosin stained sections revealed infiltrative malignant epithelial neoplasm with areas of squamous and glandular differentiation (Figure 2). The

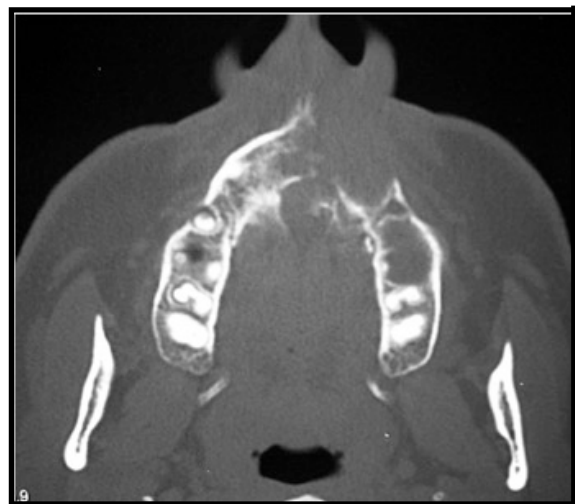

(a)

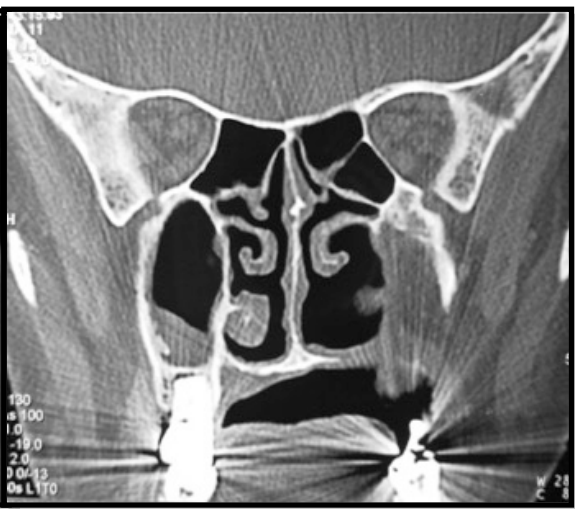

(b)

Figure 1. Computed tomography showing the involvement of the lesion. Axial reconstruction showing hypodense areas of diffuse osteolysis in the anterior alveolar ridge in both maxillas, with poorly defined margins (a) extending to the left nasal cavity and maxillary sinus (b).

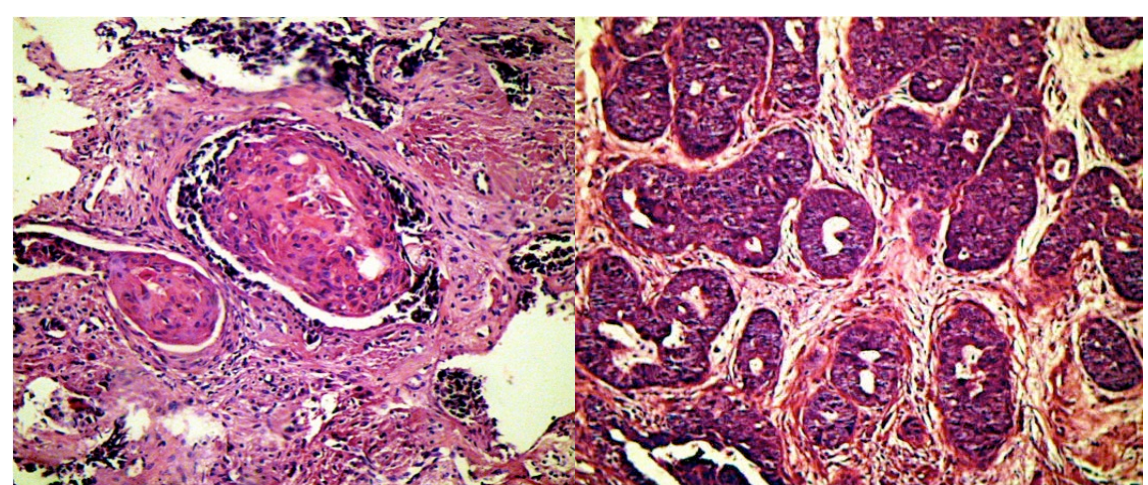

(a)

(b)

Figure 2. Histopathological features of the lesion. Invasive neoplastic growth composes of atypical squamous cells arranged in sheets or solids in nests (a). HE $200 \times$. Duct-like structures lined by a single or double layer (b). HE $200 \times$. 
tumor showed atypical cells arranged in sheets or solids in nests. The squamous component showed areas of epithelial dysplasia and carcinoma in situ. Perineural and extensive bone invasion were observed. The mucicarmine stain revealed glandular mucus-secreting neoplastic elements. In addition, immunohistochemical evaluation was performed with monoclonal/polyclonal antibodies to cytokeratins 34bE12 and CK7, and against carcinoembryonic antigen (CEA), epithelial membrane antigen (EMA), cErb-B2, chromogranin, estrogen receptor, progesterone receptor, thyroid transcription factor (TTF-1) and actin. The immunohistochemical findings are summarized in Table 2. Sections stained with $34 \mathrm{bE} 12$ and EMA showed positive immunoreactivity with both the squamous and adenocarcinoma components (Figure 3(a)). Sections stained with CK7 (Figure 3(b)) and CEA revealed positive immunoreactivity with the adenocarcinoma component only, and negative immunoreactivity with the squamous component. The final microscopic diagnosis was ASC. The patient was staged as having a T4 N1 M0 adenosquamous carcinoma of the maxilla. The treatment consisted of right and left partial maxillectomy and unilateral supraomohyoid neck dissection followed by postoperative radiotherapy with 68 Gy delivered in 35 fractionations. The histopathological examination revealed two positive lymph nodes in level I in the surgical neck specimen.

In following 6 years, the patient had two relapses, which were treated through maxillectomies and left orbit exenteration (Figure 4). These relapses occurred 4 and 8 months after the end of radiotherapy in the left and right radiotherapy, respectively.

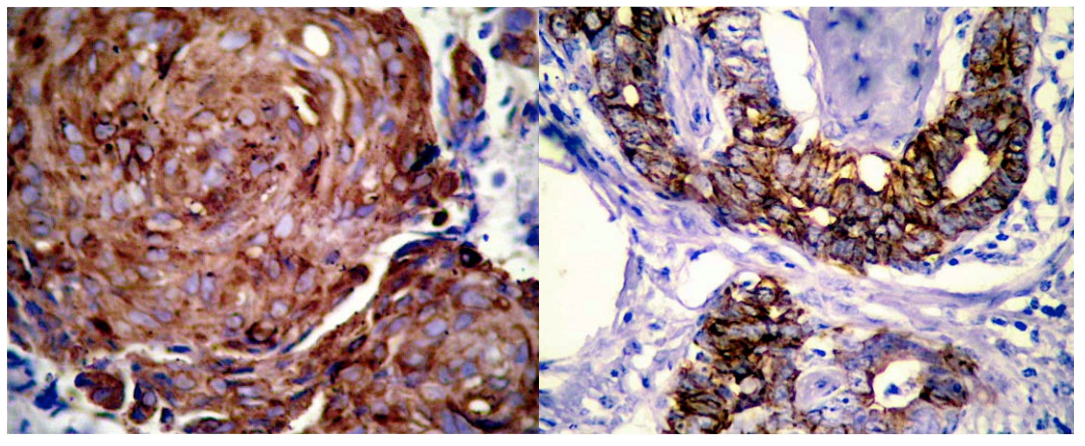

(a)

(b)

Figure 3. Presence of immunostaining for cytokeratin 34BE12 protein in the areas of the squamous epithelium. $400 \times$ (a). Presence of immunostaining for cytokeratin CK7 protein in the areas of the epithelium that presented invasive features, indicating a glandular phenotype differentiation $400 \times(\mathrm{b})$.

Table 2. Immunohistochemical findings.

\begin{tabular}{ccccccccccc}
\hline & $34 \mathrm{bE12}$ & $\mathrm{CK7}$ & $\mathrm{CEA}$ & EMA & cErbB-2 & Chromogranin & $\begin{array}{c}\text { Estrogen } \\
\text { receptor }\end{array}$ & $\begin{array}{c}\text { Progesterone } \\
\text { receptor }\end{array}$ & TTF-1 & Actin \\
\hline $\begin{array}{c}\text { Squamous } \\
\text { component }\end{array}$ & + & - & - & + & - & - & - & - & - \\
$\begin{array}{c}\text { Adenocarcinoma } \\
\text { component }\end{array}$ & + & + & + & + & - & - & - & - & - & - \\
\hline
\end{tabular}




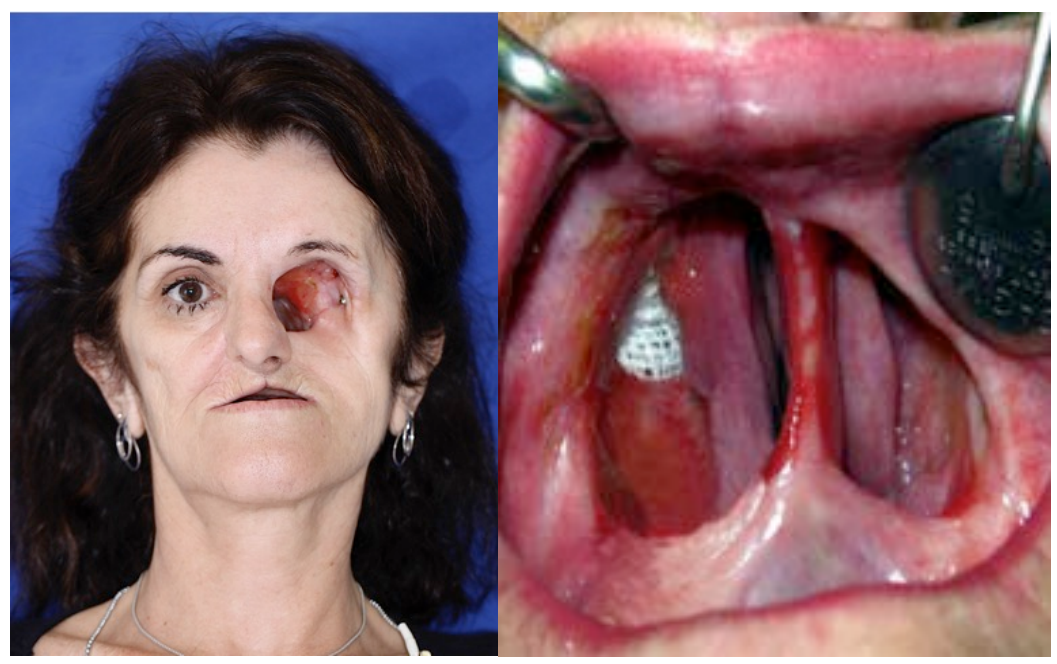

(a)

(b)

Figure 4. Extraoral and intraoral clinical presentation after bilateral total maxillectomies and the left orbit exenteration ((a) \& (b)).

The oral and maxillofacial rehabilitation of the patient began six months after the end of radiotherapy in the head and neck region. Initially, a diagnosis and treatment plan for implant-supported oral obturator and maxillofacial prostheses was presented to the patient. Implant placement was performed with the patient under general anesthesia and treated according to a 2-stage surgical implant procedure. Osseointegrated implants were installed in the upper left orbital margin and in the right zygoma (Figure 5). The planning of maxillofacial rehabilitation consisted of making two implant-supported prostheses. The definitive facial prosthesis was fabricated using silicone elastomer (VST50F; Factor II, Lakeside, AZ) that was colored intrinsically and extrinsically to match the patient's skin tone (Figure 6(a)). The obturator prosthesis was made of acrylic resin (Figure 6(b)). Magnets were used to provide retention and stability for both prostheses. Currently, the patient is under clinical and imaging follow-up, without any evidence of local recurrence or distant metastasis.

\section{Discussion}

ASC of the head and neck has been considered to be a very aggressive neoplasm with a poor prognosis. ASC is a rare neoplasm, not only in the head and neck region, but also in other areas [2] [3] [4]. Cases have also been reported in the uterine cervix, pancreas, lung, thyroid and esophagus. In the head and neck region, ASC occurs over a broad age range ( 34 to 81 years) and is 2 to 4 times more common in men [2] [3] [4] [5]. The most common sites of occurrence appear to be the larynx and the oral cavity [2]. The current case illustrates an ASC involving the maxilla, but the exact origin of this neoplasm could not be asserted due to the identification of maxillary bone invasion at the time of initial clinical examination. This fact led to difficulties in establishing the exact origin of this tumor that included nasal and oral cavities and maxillary sinus [18]. 


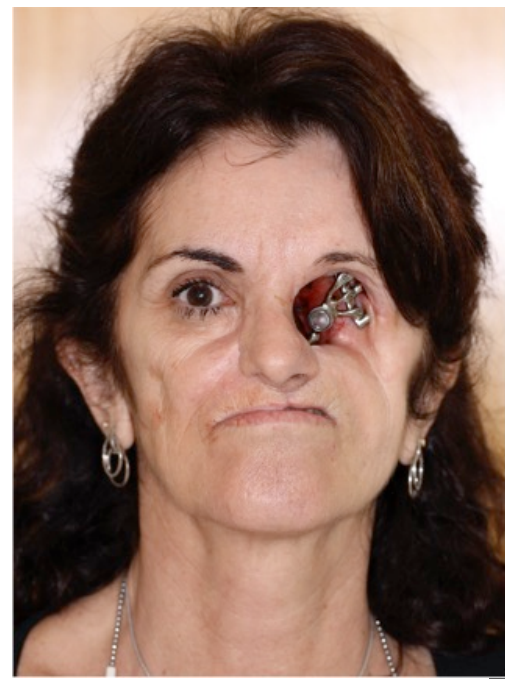

(a)

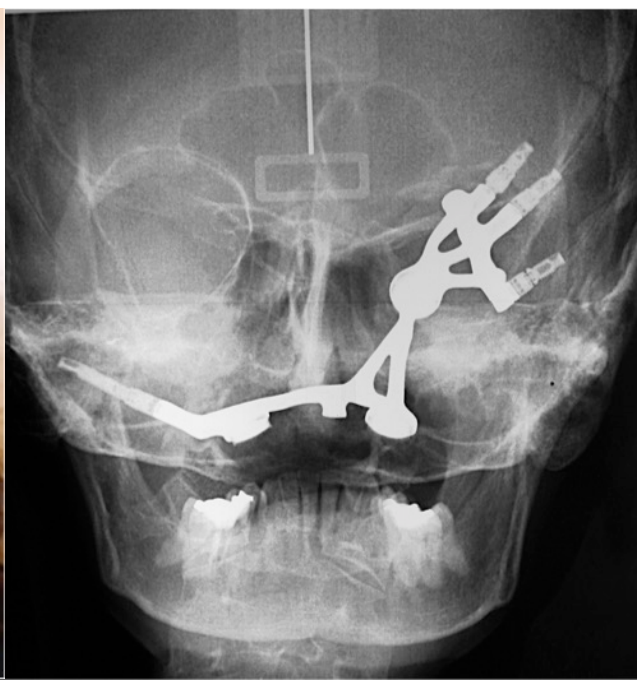

(b)

Figure 5. Osseointegrated implants installed in the upper left orbital margin and in the right zygoma with the metal framework superstructure positioned in the patient ((a) \& (b)).

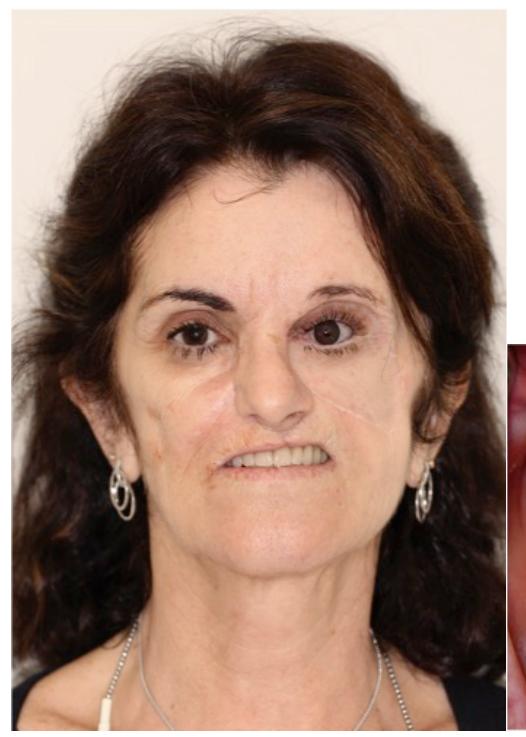

(a)

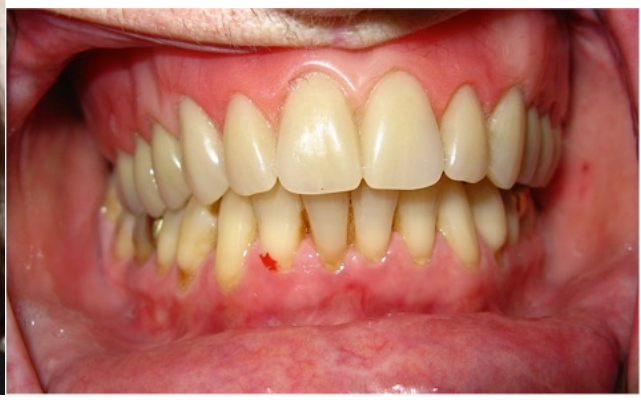

(b)

Figure 6. Final clinical aspect of the patient's facial (a) and oral (b) rehabilitation.

The recognition of ASC of the head and neck, as a distinct entity, was controversial for many years. Differential diagnosis should be specially done from squamous cell carcinoma, mucoepidermoid carcinoma, and other metastatic tumors. Histological diagnosis of ASC is often difficult for the pathologist because of the small biopsy specimens that lack either component, particularly the adenocarcinomatous one, which often exists in the deeper portion of the lesion. The SCC component which can be in situ or invasive usually predominates, and the adenocarcinoma component can have a tubular, alveolar and/or glandular morphology. In the present case, ASC is an appropriate diagnosis because of the com- 
bination of distinct areas of adenocarcinoma and SCC in both biopsy and resection specimens. This appearance contrasts with the intimate intermingling of glandular and squamous components commonly seen in mucoepidermoid carcinoma, a tumor that may arise in the oral cavity from minor salivary glands and that also exhibits a dual histomorphology [19]. Mucoepidermoid carcinoma is also characteristically associated with intermediate or transitional cells, and these are also lacking in ASC. Further evidence to support a diagnosis of ASC may be obtained using immunohistochemistry, which demonstrates distinctive staining patterns in each of the two components. Thus, in the present case, the phenotypical characteristics of the adenocarcinomatous component were emphasized by the immunoreactivity with $34 \mathrm{bE} 12, \mathrm{CK} 7, \mathrm{CEA}$ and EMA, while the phenotypical characteristics of the squamous component were demonstrated by the positive immunoreactivity with $34 \mathrm{bE} 12$ and EMA and the negative immunoreactivity with CK7 and CEA.

ASC is an aggressive tumor characterized by local recurrences, early lymph node metastasis and distant disseminations after treatment. The treatment of choice for ASC has not yet been standardized, but it seems a consensus that the best treatment option should be surgical resection with an adequate safety margin. Additional post-operative therapies, such as radiotherapy and chemotherapy, are not yet consensus on the handling of this clinical entity. Most of the reported cases in the oral cavity and maxillofacial area have been locally and extremely aggressive showing marked infiltration and destruction of the adjacent hard tissue, regardless of the radical surgical treatment and postoperative adjuvant therapies. The poor outcome of ASC of the head and neck region has been reported in the literature. Schick et al (2013) reported a 3-year overall survival rate of 52\% and a mean survival time of 39 months [5]. Keelawat et al. (2002) reported a 5-year survival rate of $20 \%$ among a series of 12 patients with adenosquamous carcinoma of the larynx, oral cavity and oropharynx [20]. Yoshimura et al.(2003) found a 5-year overall survival rate of $61 \%$ in patients who underwent an active treatment [21]. The reasons for the aggressive behavior of ASC are unclear; however it could be explained by an apparent propensity to spread by perineural invasion [17]. This histopathological feature has been reported to be present in 6 of the 12 cases in Keelawat's series [20], and in 75\% of the patients reported by Sheahan et al. The current case showed a local extreme aggressive behavior with infiltration and destruction of the maxilla and regardless of radical surgical approach and post-operative radiation therapy the patient presented 2 relapses in the first year of follow-up.

Prosthodontic rehabilitation of head and neck cancer patients is a challenging and demanding procedure. Radiation and aggressive surgical resection frequently result in functional disabilities and esthetic deformity. Oral and maxillofacial rehabilitation using conventional prostheses may be compromised or impossible to achieve due to impairment or absence of supporting tissues after surgery. Since Brånemark and Albrekttsson introduced percutaneous craniofacial implants to be used with bone conduction hearing aids, implants have also 
acquired an important role in the prosthetic rehabilitation of patients with craniofacial defects. We have previously reported our experience with implant-supported craniofacial prostheses for the management of patients with head and neck cancer. In this study, the survival rate of implants placed in the orbital region was $100 \%$. Some clinical studies have also reported survival rates higher than $90 \%$ for orbital implants, which seems to be a predictable result [22]. However, in the current case the implants were installed outside of the primary tumor irradiation field, which allowed more predictable implants and prostheses outcome. The optimal timing of implant placement in head and neck patients is controversial. Some authors recommend the installation of implants during ablative tumor surgery. Insertion of implants at this time would be of great advantage because the initial implant healing occurs before irradiation and, thus, minimizes the risk of late oral complications, such as the development of osteoradionecrosis. The rehabilitation of maxillofacial deformities in head and neck cancer patients using implant-supported prostheses allows direct access to the cavities for searching an eventual tumor local recurrence. Fortunately, the use of cosmetic and restorative therapy has improved the quality of life of patients with disfiguring diseases.

\section{Conclusion}

In conclusion, ASC is an aggressive tumor characterized by local recurrences. Although ASC rarely affects the maxilla, the dentist also has an important role in the diagnosis, rehabilitation treatment and patients' follow-up of patients, improving their quality of life.

\section{References}

[1] Gerughty, R.M., Hennigar, G.R. and Brown, F.M. (1968) Adenosquamous Carcinoma of the Nasal, Oral and Laryngeal Cavities: A Clinico-Pathologic Survey of Ten Cases. Cancer, 22, 1140-1155.

https://doi.org/10.1002/1097-0142(196811)22:6<1140::AID-CNCR2820220610>3.0. CO;2-1

[2] Barnes, L., Tse, L.L.Y. and Hunt, J.L. (2005) Tumors of the Hypopharynx, Larynx, and Trachea: Introduction. In: Barnes, E.L., Eveson, J.W., Reichart, P., Sidransky, D., Kleihues, P. and Sobin, L.H., Eds., Pathology and Genetics of Head and Neck Tumors, World Health Organization Classification of Tumors, IARC 11, Lyon.

[3] Fonseca, F.P., Ramos, L.M., Vargas, P.A., De Almeida, O.P., Lopes, M.A. and Santos, S.A.R. (2012) Oral Adenosquamous Carcinoma: Evidence That It Arises from the Surface Mucosal Epithelium. Histopathology, 61, 321-323.

https://doi.org/10.1111/j.1365-2559.2012.04257.x

[4] Scully, C., Porter, S.R., Speight, P.M., Eveson, J.W. and Gale, D. (1999) Adenosquamous Carcinoma of the Mouth: A Rare Variant of Squamous Cell Carcinoma. International Journal of Oral and Maxillofacial Surgery, 28, 125-128.

[5] Schick, U., Pusztaszeri, M., Betz, M., Ghatjar, P., Demiroz, C., Kaanders, J.H. and Ozsahin, M. (2013) Adenosquamous Carcinoma of the Head and Neck: Report of 20 Cases and Review of the Literature. Oral Surgery, Oral Medicine, Oral Pathology, Oral Radiology, 116, 313-320.

[6] Napier, S.S., Gormely, J.S., Newlands, C. and Ramsay-Baggs, P. (1995) Adenosqua- 
mous Carcinoma. A Rare Neoplasm with an Aggressive Course. Oral Surgery, Oral Medicine, Oral Pathology, Oral Radiology, and Endodontology, 79, 607-611.

[7] Alos, L., Castillo, M., Nadal, A., Caballero, M., Mallofre, C., Palacin, A. and Cardesa, A. (2004) Adenosquamous Carcinoma of the Head and Neck: Criteria for Diagnosis in a Study of 12 Cases. Histopathology, 44, 570-579.

https://doi.org/10.1111/j.1365-2559.2004.01881.x

[8] Sheahan, P., Toner, M. and Timon, C.V. (2005) Clinicopathological Features of Head and Neck Adenosquamous Carcinoma. ORL, 67, 10-15. https://doi.org/10.1159/000083008

[9] Sanner, J.R. (1979) Combined Adenosquamous Carcinoma and Ductal Adenoma of the Hard and Soft Palate: Report of Case. Journal of Oral Surgery, 37, 331-334.

[10] Minić, A.J. and Stajcić, Z. (1994) Adenosquamous Carcinoma of the Inferior Turbinate: A Case Report. Journal of Oral and Maxillofacial Surgery, 52, 764-767.

[11] Som, P.M., Silvers, A.R., Catalano, P.J., Brandwein, M. and Khorsandi, A.S. (1997) Adenosquamous Carcinoma of the Facial Bones, Skull Base, and Calvaria: CT and MR Manifestations. American Journal of Neuroradiology, 18, 173-175.

[12] Shinhar, S.Y. and Heckathorn, C.L. (2008) Adenosquamous Carcinoma of the Nasal Cavity. Ent-Ear Nose \& Throat Journal, 87, 612-614.

[13] Suzuki, S., Hanata, K., Nanjo, H. and Ishikawa, K. (2009) Adenosquamous Carcinoma of Maxillary Sinus: Case Showing Complete Response to S-1. The Journal of Laryngology \& Otology, 123, 1271-1275. https://doi.org/10.1017/S0022215109004538

[14] Masand, R.P., El-Mofty, S.K., Ma, X.J., Luo, Y., Flanagan, J.J. and Lewis, J.S. (2011) Adenosquamous Carcinoma of the Head and Neck: Relationship to Human Papillomavirus and Review of the Literature. Head and Neck Pathology, 5, 108-116. https://doi.org/10.1007/s12105-011-0245-3

[15] Kumar, R. and Issing, W. (2011) Orbital Cellulitis: A Rare Presentation of Metastatic Bronchial Carcinoma. Case Reports in Otolaryngology, 2011, Article ID: 397451. https://doi.org/10.1155/2011/397451

[16] Bishop, J.A., Guo, T.W., Smith, D.F., Wang, H., Ogawa, T., Pai, S.I. and Westra, W.H. (2013) Human Papillomavirus-Related Carcinomas of the Sinonasal Tract. The American Journal of Surgical Pathology, 37, 185-192. https://doi.org/10.1097/PAS.0b013e3182698673

[17] Thanakappan, P., Venkata, N.S., Amudala, R. and Botu, M. (2015) Adenosquamous Carcinoma of Oral Cavity. Journal of Cancer Research and Therapeutics, 11, 1034. https://doi.org/10.4103/0973-1482.154054

[18] Takeuchi, T., Yasui, T., Izeki, M. and Komune, S. (2015) Adenosquamous Carcinoma of Unknown Primary Origin: A Case Report and Literature Review. The Journal of Laryngology \& Otology, 129, S91-S94. https://doi.org/10.1017/S0022215114002473

[19] Sheahan, P., Fitzgibbon, J., Lee, G. and O’Leary, G. (2003) Adenosquamous Carcinoma of the Tongue in a 22-Year-Old Female: Report of a Case with Immunohistochemistry. European Archives of Oto-Rhino-Laryngology, 260, 509-512. https://doi.org/10.1007/s00405-003-0616-9

[20] Keelawat, S., Liu, C.Z., Roehm, P.C. and Barnes, L. (2002) Adenosquamous Carcinoma of the Upper Aerodigestive Tract: A Clinicopathologic Study of 12 Cases and Review of the Literature. American Journal of Otolaryngology, 23, 160-168. https://doi.org/10.1053/ajot.2002.123462

[21] Yoshimura, Y., Mishima, K., Obara, S., Yoshimura, H. and Maruyama, R. (2003) Clinical Characteristics of Oral Adenosquamous Carcinoma: Report of a Case and an Analysis of the Reported Japanese Cases. Oral Oncology, 39, 309-315. 
[22] Curi, M.M., Oliveira, M.F., Molina, G., Cardoso, C.L., Oliveira, L.G., Branemark, P.I. and Ribeiro, K.C. (2012) Extraoral Implants in the Rehabilitation of Craniofacial Defects: Implant and Prosthesis Survival Rates and Peri-Implant Soft Tissue Evaluation. Journal Oral Maxillofacial Surgery, 70, 1551-1557.

https://doi.org/10.1016/j.joms.2012.03.011

Submit or recommend next manuscript to SCIRP and we will provide best service for you:

Accepting pre-submission inquiries through Email, Facebook, LinkedIn, Twitter, etc. A wide selection of journals (inclusive of 9 subjects, more than 200 journals)

Providing 24-hour high-quality service

User-friendly online submission system

Fair and swift peer-review system

Efficient typesetting and proofreading procedure

Display of the result of downloads and visits, as well as the number of cited articles Maximum dissemination of your research work

Submit your manuscript at: http://papersubmission.scirp.org/

Or contact jct@scirp.org 